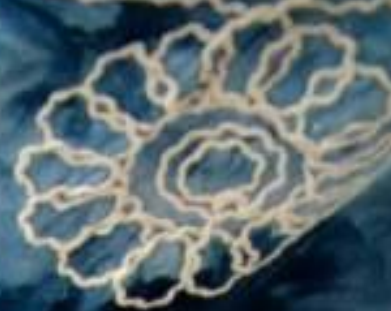

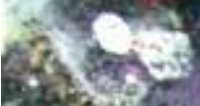

* tas
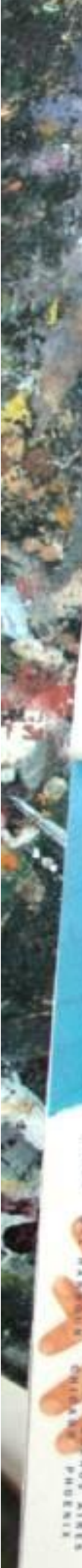

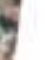

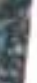
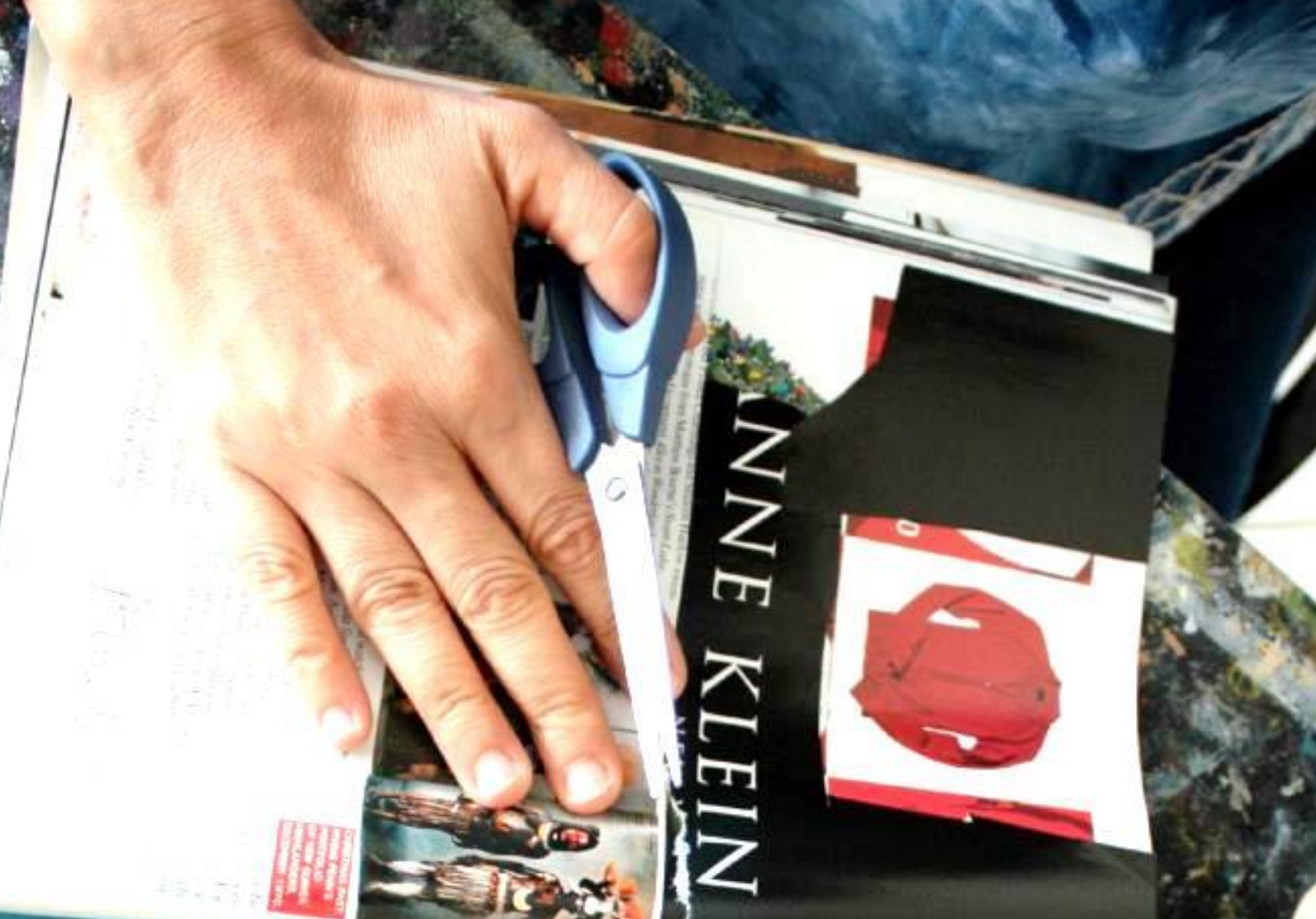


\section{REVISTA APOTHEKE}

\section{v.6, n.1, ano 3, julho de 2017 \\ ISSN 2447-1267}

\section{RACE, ETHINICITY, GENDER, RELEVANCE , POLITICS, AND WHAT YOU TEACH.}

Tradução do capítulo I do Livro: JAFFE, Nick; BARNISKIS, Becca \& COX, Barbara Hackett. Teaching Artist Handbook, V. I: Tools, Techniques and Ideas. Chicago: Columbia College Chicago Press, 2013, p. 16-27. Tradução livre: Juliano Siqueira, doutorando no PPGAV/UDESC ${ }^{49}$

\section{RAÇA, ETNICIDADE, GÊNERO, RELEVÂNCIA, POLÍTICA E O QUE VOCÊ ENSINA}

Como artistas educadores nós estamos bem posicionados para lutar pelos direitos dos estudantes para que eles possam trabalhar com o mais amplo espectro de temáticas e possibilidades artísticas possíveis. Esta é uma batalha que nós temos que lutar em duas frentes: exclusão da arte e dos artistas das comunidades oprimidas e marginalizadas e "typecasting" 50 e construção de estereotipo destes artistas. Nós precisamos trabalhar contra noções estreitas de "arte elevada", fazer visíveis as razões por trás da construção de tais categorias e os modos como estas categorias são usadas e rejeitar a marginalização e trivialização histórica de artistas e tradições artísticas inteiras que é endêmica na história e no presente de nosso país.

Artistas educadores vêm em todas as raças, cores, credos, gêneros e identidades sexuais e cada um de nós carrega conosco toda uma gama de experiências e tradições pessoais e culturais. Algumas de nossas experiências nós podemos considerar ricas e úteis para nós enquanto artistas e enquanto artistas educadores. Outras nós podemos sentir como limitantes e opressoras. Algumas talvez tenham deixado cicatrizes em nós. Nossos estudantes não são diferentes e

49 Tradução realizada na disciplina Sobre ser Artista Professor.2015.2. Ministrante: Profa. Dra. Jociele Lampert.

50 Dar papéis-tipos. 


\section{REVISTA APOTHEKE}

\section{v.6, n.1, ano 3, julho de 2017 \\ ISSN 2447-1267}

assim como nós, enquanto artistas, escolhemos refletir, redefinir, transcender, ignorar ou desafiar nossas próprias identidades em nosso fazer artístico, assim também nossos estudantes deveriam ter esta escolha e margem de expressão disponível para eles.

Também não é exagero o quão transformativo pode ser para os artistas-estudantes trabalhar ao lado de artistas com quem eles possam se identificar, seja por causa da cor da pele, classe, gênero, sexualidade, circunstância social ou pessoal. Em uma sociedade que agressivamente fala às pessoas jovens de mil formas todos os dias o que elas "podem" e o que elas "não podem", para um estudante fazer uma conexão pessoal com um artista que desafia esses estereótipos pode ser liberador em si mesmo. Aprender e colaborar com tais artistas pode mudar a vida de um estudante, quer este estudante se torne um artista ou não. Por estas razões e também porque artistas de cor, artistas imigrantes, artistas indígenas, artistas mulheres e artistas LGBT são sub-representados nos rankings de artistas educadores e nas lideranças do nosso campo, deve ser parte do nosso trabalho conjunto trazer mais destes artistas para o campo e para a liderança e dar a todos os estudantes mais acesso e experiência à diversidade total de artistas.

Educação nos Estados Unidos é racialmente segregada separada e profundamente desigual. Muitas escolas que atendem a estudantes de cor não têm acesso aos recursos desfrutados pelas escolas mais influentes que tipicamente atendem estudantes brancos. O trabalho dos artistas educadores esta inevitavelmente preso a esta realidade de desigualdade e segregação. Alguns programas e financiamentos para as artes muitas vezes são tentativas de falar sobre o acesso desigual às artes e alguns programas visam especificamente trazer para as escolas artistas que 


\section{REVISTA APOTHEKE}

\section{v.6, n.1, ano 3, julho de 2017 \\ ISSN 2447-1267}

se aproximem mais do background dos alunos. Enquanto área nós precisamos lutar para que os estudantes tenham acesso a todos os artistas e para que todos os artistas tenham acesso a este trabalho.

Também é importante lembrar que a experiência de trabalhar como artista - tendo agência artística real fazendo um trabalho que você concebe e que expressa o que você quer expressar - pode ser liberador e pode algumas vezes até mesmo salvar pessoas, especialmente pessoas jovens, em circunstâncias terrivelmente difíceis. Nós estamos pensando aqui em pessoas jovens que nós conhecemos, e sabemos a respeito, que têm tido o prazer de trabalhar em estúdios ou programas realmente fortes liderados por artistas educadores e que vieram a ver a si mesmos como artistas e se conhecer como tal mesmo que eles não tenham continuado a fazer arte. Nestes contextos eles frequentemente formam alianças com seus pares, com os artistas educadores e mesmo com os administradores de programas, formam relações que são relações de artista para -artista. A vida é realmente difícil para a maioria das pessoas jovens na América (US), especialmente para jovens de cor. Quando uma pessoa jovem está lutando para permanecer no ensino médio ou na faculdade, ou talvez mesmo para achar comida e uma cama, o fato de que ele ou ela teve aquela agência como artista e criou aquelas relações pode fazer uma grande diferença. Pode ser que eles venham a se aproximar de um colega, artista educador ou administrador de um programa para buscar conselho ou ajuda porque eles sabem que serão recebidos não apenas como alguém em crise, mas como um colega artista. Ou pode ser simplesmente que quando você estiver realmente se sentindo para baixo, lembrar que você é de fato um artista é a coisa que tira você disso. Nós não queremos dizer "lembrar que você é um artista" num sentido abstrato ou místico, em vez disso 


\section{REVISTA APOTHEKE}

\section{v.6, n.1, ano 3, julho de 2017 \\ ISSN 2447-1267}

queremos dizer lembrar que você tem algumas habilidades específicas num meio que permite a você fazer um trabalho que importa para você e para outros e que você sempre terá este prazer, esta válvula de escape e este poder disponível para você. Lembrar que o reconhecimento tem certamente nos tirado de alguns dias ruins.

Isto não é para dizer que o trabalho do artista educador é um trabalho social - confundir como tal é tanto perder $\circ$ ponto quanto trivializar o trabalho poderoso $e$ vital que os assistentes sociais de verdade fazem. Em vez disso, o ponto é que o trabalho do artista educador permite a qualquer um de nós nos descobrirmos enquanto artistas, contribuir enquanto artistas e ajudar um ao outro enquanto artistas.

Em várias disciplinas, expectativas estereotipadas sobre artistas e estudantes baseadas em suas raízes culturais podem desnecessariamente estreitar o senso de um estudante acerca do que é possível fazer ou criar. Em vez de expandir as possibilidades para artistas e estudantes, tais nichos replicam e amplificam os efeitos limitantes da opressão. Artistas de cor frequentemente têm a experiência de serem contratados com a expectativa de que irão trazer experiências de aprendizagem em artes culturalmente específicas para os estudantes. Isso pode ser frequentemente traduzido como a estereotipagem de artistas negros, latinos e asiáticos, por exemplo, o poeta lírico negro do qual se espere que ensine hip hop ou "spoken Word" ${ }^{1}$, ou ao qual se pede para tratar apenas de certos temas (empoderamento, comunidade, não violência) mesmo quando estes temas não têm nada a ver com o trabalho dele ou dela.

Como artistas educadores nós sabemos pela experiência que arte boa é arte boa. Qualquer arte, qualquer terreno de

51 Palavra-falada (estilo de poesia da comunidade Afro Americana). 


\section{REVISTA APOTHEKE}

\section{v.6, n.1, ano 3, julho de 2017 \\ ISSN 2447-1267}

conhecimento pode ser relevante para qualquer pessoa. Alguns educadores põem muitas fichas na ideia de que conteúdo e ensino têm que ser relevante para a experiência individual de um estudante para que este estudante se engaje e "aprenda". Isto é frequentemente entendido como dizer que o que é ensinado em sala de aula deveria sempre estar relacionado ao que o estudante já conhece e gosta. Acontece que nós pensamos que esta noção é ridícula e tem consequências particularmente negativas para o trabalho dos artistas educadores.

Antes de mais nada, esta ideia está baseada em algumas suposições questionáveis sobre os estudantes. A premissa de que certos grupos de estudantes gostam de certas coisas. Na prática isso frequentemente aparece como um tipo de estereótipo: "estudantes urbanos em risco" em uma escola pública em Chicago vão gostar de hip hop. Assim sendo, se eu ensino música eu devo ensinar hip hop, ou ao menos relacionar minha prática de ensino ao hip hop. É claro que estudantes de todas as cores e backgrounds nas escolas públicas de Chicago gostam de todos os tipos de música e experienciaram todos os tipos de música; clássico, jazz, gospel, metal, punk rock, country, etc. alguns gostam de um tipo de música mais do que de outro; alguns se identificam mais com um gênero do que com outro. Nossos estudantes são indivíduos com todos os tipos de gostos e experiências. Se nós estamos aqui com o papel de ajudar os estudantes a desenvolver a sua arte, então nós devemos começar reconhecendo que eles têm gostos e experiências únicas em que se basear.

Outro problema com esta ideia estréia de relevância é que ela implica que apenas algumas culturas são apropriadas e acessíveis para algumas pessoas. O fato é que estudantes jovens são fortemente puxados para o que é não familiar e para a novidade. Crianças são onívoros culturais e assim 


\section{REVISTA APOTHEKE}

\section{v.6, n.1, ano 3, julho de 2017 \\ ISSN 2447-1267}

também o são muitos adultos. Se acontece de você ter muitos estudantes que estão seriamente engajados com o hip hop então você sabe que entre os gêneros musicais o hip hop é talvez o mais onívoro e eclético. Sua própria premissa é a de combinar o que é estranho, disparatado e reciclado violando todas as regras de gêneros musicais e suas expectativas. Tudo diz respeito a justapor steely Dean, Stravinsky e Jabo Starks. Pressupor o que vai ser de interesse cultural para um estudante é diminuir o acesso do estudante ao material primário que deu origem á expressão artística dele ou dela. Esperar que os estudantes queiram fazer arte apenas sobre quem eles são e onde eles estão no sentido mais literal só pode ser um obstáculo para a criação artística real. Nós não esperaríamos que um artista profissional que é negro vá lidar com negritude, ou uma artista mulher que tem crianças a fazer arte sobre a maternidade. Nós não deveríamos esperar tais coisas de jovens artistas tampouco. Alguns artistas fazem trabalhos sobre si mesmos. Outros fazem trabalhos precisamente para escapar de sua própria experiência e meio ou para redefinir a si mesmos, em seus próprios termos. Muitos artistas não lidam diretamente com o "self" de modo algum. Estudantes de artes deveriam ter, em seu processo de criação artística, a ampla gama de chances disponíveis para eles.

Enquanto artistas educadores nós estamos exatamente na posição certa para explorar essa noção particular de relevância que está baseada na fantasia de alguém sobre quem nossos estudantes são, e para ajudar nossos estudantes a construir a sua própria noção de relevância baseada no que eles ouvem, veem, sentem e pensam. Se o que você sabe é ópera italiana do século XVIII não se preocupe se é ou não relevante para os estudantes. É uma música fascinante e que você conhece e ama. Se você traz este conhecimento e paixão para os estudantes e cria um contexto no qual eles podem 


\section{REVISTA APOTHEKE}

\section{v.6, n.1, ano 3, julho de 2017 ISSN 2447-1267}

explorar aquela música e fazer alguma coisa deles mesmos com ela, então será mais do que relevante, será a arte deles.

Nós artistas educadores precisamos advogar pela nossa própria forma de arte e pela de outros artistas educadores, a fim de sermos respeitados tanto enquanto parte de qualquer grupo com o qual tenhamos escolhido nos identificar - se nós escolhemos assim nos identificar - e tanto enquanto artistas individuais, com vozes individuais. Se nós não nos erguemos por liberdade artística verdadeira para ambos, estudantes e artistas educadores, nós arriscamos nos tornarmos uma vitrine pomposa cobrindo os contextos opressivos e desiguais nos quais ensinamos.

Muitos artistas engajam com temas políticos e sociais em seu trabalho ou trabalham parcialmente ou totalmente a partir de um desejo de fazer alguma mudança política ou cultural. Se você é um artista político fora de contextos educacionais, então é claro que você deve ser livre para trabalhar como um que está em contextos educacionais. Alguns artistas educadores lecionam porque eles sentem que através do ensino eles podem trazer alguma mudança social ou ter algum impacto particular sobre as visões políticas, morais ou espirituais dos seus estudantes. Estas são talvez tão boas razões quanto quaisquer outras para trazer o 'eu' do artista para dentro da sala de aula ou outro contexto educacional. No entanto, em alguns casos artistas educadores, frequentemente com as melhores das intenções, permitem que seu ensino se torne didático, de maneiras que têm mais a ver com os seus próprios pontos de vista do que um meio de abrir um espaço para que os estudantes expressarem suas próprias ideias em um medium ${ }^{52}$. Isto pode

52 MEDIUM: pode ser traduzida como meio ou material. Em alguns contextos do texto pode também ser traduzido como meio artístico, material artístico, material expressivo ou forma expressiva. Optou-se por manter o termo medium em toda tradução. 


\section{REVISTA APOTHEKE}

\section{v.6, n.1, ano 3, julho de 2017 \\ ISSN 2447-1267}

levar a um trabalho no qual os estudantes não aprendem muito sobre um medium ou mesmo sobre a questão ou ponto de vista particular que está informando o trabalho do artista educador. Aqui estão algumas questões que alguém pode querer considerar quando pensa como e se deve engajar sua própria política e visões de mundo no planejamento curricular e na prática docente:

1. Você está mais interessado em instruir os estudantes em um ponto de vista moral, espiritual, cultural ou político particular, ou você está primeiramente interessado em ajudá-los a desenvolverem suas próprias visões artísticas em um medium? Se a primeira alternativa é o caso, então talvez você devesse se apresentar como um professor morall espirituallcultural lpolitico que usa o fazer artístico, ao invés de primordialmente como um artista educador.

2. Você está interessado em apresentar suas ideias ou visões politicas como um meio de estimular seus estudantes a pensar independentemente e criticamente e fazer um trabalho original no seu material? Ou você está mais interessado em fazê-los pensar como você?

3. Você está assumindo que os seus estudantes todos têm uma visão particular sobre um assunto ou questão histórica, ou você os aborda como pensadores politicos individuais com seus próprios pontos de vista individuais?

4. Você está assumindo que todos os seus alunos compartilham um entendimento I senso particularl específico sobre a sua própria identidade social, cultural, política ou você os está abordando como 


\section{REVISTA APOTHEKE}

\section{v.6, n.1, ano 3, julho de 2017 \\ ISSN 2447-1267}

artistas individuais, cada qual com uma maneira única de ver as coisas, ainda que informada pelo seu contexto social ou cultural?

5. Está bem para você se os seus alunos criam um trabalho que é alternativo ou mesmo oposto ao seu ponto de vista? Você está encorajando isto enquanto uma possibilidade?

6. Você quer que seus estudantes vejam você como um artista crítico e questionador que desenvolveu uma visão de mundo particular, ou você quer que eles o vejam como alguém que tem a visão de mundo "correta"?

7. Você quer empoderar os seus estudantes ensinando-os a ver o mundo como você vê, ou você quer empoderálos lhes equipando com algumas ferramentas artísticas com as quais eles podem investigar e dar forma ao mundo do modo que eles pensam que é necessário e importante?

Nós queremos deixar claro que não estamos arguindo contra engajar com temas políticos ou mesmo controversos no trabalho de artistas educadores. Nós não estaríamos engajando os estudantes enquanto artistas se não os desafiássemos a olhar para o mundo em volta deles criticamente e ver a realidade social e política como matéria prima para o comentário e a expressão artística. Nós não seríamos arte educadores se não nos sentíssemos livres para trazer nossos próprios conflitos e opiniões em nossas discussões e trocas com os estudantes. Se fizermos estas coisas de maneira a dar tempo e espaço para os estudantes desenvolverem seus próprios pontos de vista intelectuais, políticos e artísticos, muito poderá ser aprendido e uma ótima criação artística poderá acontecer. Mas se nós tivermos um resultado pré determinado em mente, 


\title{
REVISTA APOTHEKE
}

\author{
v.6, n.1, ano 3, julho de 2017 \\ ISSN $2447-1267$
}

um que prescinda da investigação real e de um processo original de criação artística então a experiência poderá ser alienante para os estudantes e uma perda de tempo.

Nós devemos ver que parte do nosso trabalho enquanto arte educadores é rejeitar estereotipar ambos: nossos estudantes e todos os artistas. Nós devemos procurar dar a mais ampla experiência artística e pessoal possível para nossos estudantes e forçar a abertura das portas das instituições educacionais e outras em que trabalhamos para permitir acesso para todos os artistas em seus próprios termos.

A única maneira de realizar o trabalho de arte educação com integridade frente às poderosas forças opressivas que o uniformizam, simplificam, integram-no em práticas de sala de aula superficiais, ou o tornam um mero meio de enxugar a lista de fins educacionais, sociais, emocionais ou políticos é colocar o rigor artístico e o processo de criação artística autêntico no centro. Nossos estudantes são artistas. Nós podemos aplicar uma regra de ouro da arte educação: não peça aos seus estudantes para fazer coisas que você próprio acharia artisticamente superficial, entediante, limitante, manipulativo, arrogante ou fútil. Sim os introduza a totalidade de possibilidades do seu medium a partir das dimensões de pensamento e prática que você considera mais interessantes e geradoras enquanto artista.

\section{- toda a cultura para todas as pessoas}

Nós não vivemos em uma sociedade pós racial. Nós vivemos em uma sociedade racista e segregada. Você não tem que ser negro, latino, árabe ou asiático para saber disso,

é só você entrar em uma escola pública urbana, centro comunitário ou prisão e você verá que separado-e-desigual 


\section{REVISTA APOTHEKE}

\section{v.6, n.1, ano 3, julho de 2017 \\ ISSN 2447-1267}

ainda é a norma pela América (E.U.A). Todas as pessoas de cor neste país encaram milhares de formas de racismo todos os dias, quanto mais escuro o tom da pele mais extremas serão as barreiras e maiores os perigos. Nenhum grau de sensibilidade pessoal ou de "celebração da diversidade" pode consertar o dano feito às pessoas e à sociedade pelo simples fato de que uma escola primária com uma superpopulação inteiramente negra em um edifício em ruínas está apenas a uma ou duas milhas de uma escola pública inteiramente branca a qual se parece com o campus de uma universidade privada. A única maneira de consertar isso é mudando isso.

Enquanto um arte educador que frequentemente trabalha em escolas segregadas por raça e classe, algumas vezes encontro expectativas bem específicas da parte dos administradores (de escolas e escolas de artes) ou dos professores - raramente por parte dos financiadores ou dos pais. Eu quase nunca encontrei estas expectativas em escolas mais abastadas, integradas ou brancas. As expectativas caem em duas categorias: 1) a expectativa de que o estudante de artes ou de música não vá lidar com temas difíceis ou sombrios; 2) a expectativa de que os estudantes irão abraçar uma interpretação específica sobre a sua própria identidade racial como o tema central no seu trabalho. Colocando mais abruptamente, crianças negras, latinas e pobres são frequentemente proibidas de fazer referência à violência e á hostilidade em seu trabalho (como se a representação levasse á ação) e as mesmas crianças são frequentemente, quase mecanicamente, encorajadas a "celebrar" representações unidimensionais do que outra pessoa imaginou ser sua herança cultural, representações estas que frequentemente nem mesmo arranham a superfície das experiências da juventude, ou a história real da qual eles, assim como todos nós estamos emergindo. 


\section{REVISTA APOTHEKE}

\section{v.6, n.1, ano 3, julho de 2017 \\ ISSN 2447-1267}

A implicação, às vezes tornada bem explícita, é de que estas crianças e jovens são incapazes de expressão e de sutileza na interpretação e que não têm uma paisagem cultural própria, ou ao menos não uma digna de se fazer arte a partir dela.

A realidade é, naturalmente, muito diferente. Nas escolas mais detonadas, nos bairros mais oprimidos e empobrecidos as crianças são inteligentes, inventivas, curiosas e mente-aberta como quaisquer outras crianças. Frequentemente elas têm uma experiência cultural mais rica e mais variada do que seus pares socialmente bem colocados. Alguns educadores bem intencionados perdem de vista este ponto completamente. Eu me lembro que uma vez quando eu estava tendo aulas para o meu certificado de professor, um "especialista em sensibilidade cultural" explanou para nós sobre como o mundo de uma criança latina imigrante estava supostamente limitado pelo punhado de blocos que delimitavam o motel depredado no qual a criança e sua família viviam. Parece que não ocorreu a este especialista, que o fato desta família ter recentemente caminhado e pedido carona todo o caminho de San Salvador até Los Angeles sugeria, outrossim, uma experiência muito mais ampla. E isso deixando de lado a suposição insidiosa de que a criança vivia uma vida limitada, culturalmente deficiente em El Salvador.

Nós não devemos esperar ou demandar diretamente ou ainda que bem sutilmente que os nossos estudantes façam uma arte sobre raça que seja palatável para nós. Ou que façam arte sobre raça e identidade tal como estas são concebidas por alguém. O fato de que um estudante cresceu negro no lado sul de Chicago não significa que ele ou ela esteja mais inclinado a Langston Hughes do que a William Blake. A criação artística é muito sobre reformular ou mesmo explodir a identidade $e$ imaginar $e$ interpretar a 


\section{REVISTA APOTHEKE}

\section{v.6, n.1, ano 3, julho de 2017 \\ ISSN 2447-1267}

experiência de outros. Isto não é sugerir não ver cor ${ }^{53}$, cor é tão profunda enquanto realidade cultural quanto o é a opressão que a define. Escritores, artistas, cientistas e historiadores de cor devem ser celebrados ainda mais porque eles são muito frequentemente "desaparecidos". Mas eles também devem ser estudados porque são escritores artistas, cientistas e historiadores.

Eu também não quero trivializar as condições, opressão oprime sim. Se você não consegue ler na $6^{a}$ série isso vai perturbar a sua cabeça. Se você tem que driblar tiroteio ou ir com fome para aula ou atender a uma escola completamente segregada isso vai mexer com a sua alma, as vezes profundamente. Se você não tem nenhum recurso financeiro ou se é muito perigoso sair do seu bairro isso vai limitar o que você vê do mundo. Se você tem que temer ser regularmente parado, ou coisa pior, por policiais ou pelo serviço de imigração por causa da cor da sua pele, isso pode te colocar para baixo e te arrebentar de mil maneiras. Mas ainda que as condições, a cor e a etnia nos marquem elas não nos definem. Cada um de nossos estudantes é único e nós perceberemos isso rapidamente se, enquanto artistas educadores nós nos relacionarmos com eles como colegas artistas.

Eu vou finalizar com um poema, que é parte de um CD produzido por estudantes no qual estudantes do $5^{\circ}$ ano colocam seus escritos sobre o Movimento pelos Direitos Civis ${ }^{54}$ em forma de músicas. Vocês podem ouvir a gravação deste poema (tal como ele foi lido pela autora com a música original - e eu acho que ele tem muito mais efeito quando ouvido com o áudio) em http \casounds.bandcamp.com\track \back-in-the-civil-rightsdays - O CD foi concebido por alunos que estudavam esta

53 Color blindness.

54 Civil Rights Movement. 


\section{REVISTA APOTHEKE}

\section{v.6, n.1, ano 3, julho de 2017 \\ ISSN 2447-1267}

história com uma professora inspirada, que irradiava o seu interesse pelo material e pelo que os estudantes pensavam sobre ele. Eu fui um privilegiado em fazer parte do projeto enquanto arte educador, porque, junto com os estudantes, nós coordenamos um estúdio numa escola na qual nós não apenas encorajamos, um ao outro, a fazer música sem limitar, censurar ou estereotipar nós mesmos, mas nós também demandamos isso para cada um de nós.

\section{De volta aos dias dos direitos civis}

De volta aos dias dos direitos civis

Negros não podiam nem se sentir

Seguros em suas próprias casas

Quero dizer, o que é isso?

Quanto mais eu penso sobre isso

A segregação realmente acabou?

Quando você caminha pela rua

Você ouve "Ô nigger"55!" ou

"Vagabundo, cai fora dessa área"

Você ouve?

Zakeira Ward $-5^{\circ}$ ano

\section{o que é essencial no seu processo artístico?}

O que, então é necessário considerar quando estiver definindo o que você vai ensinar na sua forma artística? Nós poderíamos argumentar que a técnica e os processos através do qual ela é aplicada são as partes ensináveis e essenciais do que torna a expressão artística possível. Os conceitos, teorias e experiências do processo artístico são importantes e ensináveis em algum grau, mas nós acreditamos que um trabalho efetivo de arte educação está enraizado em processos e técnicas de trabalho sobre um medium. Alguma técnica pode ser aprendida organicamente através da

\footnotetext{
55 O termo não tem uma tradução literal no português- designa a inferioridade de uma pessoa negra. Considerada uma das palavras mais ofensivas da língua inglesa. "N-word."
} 


\section{REVISTA APOTHEKE}

\section{v.6, n.1, ano 3, julho de 2017 \\ ISSN 2447-1267}

experiência, imitação ou experimentação intuitiva: muitas crianças e alguns adultos aprendem a dançar, desenhar ou cantar muito bem sem nenhuma instrução formal. Os estudantes não precisam de nós para fazer arte - eles o fazem com ou sem a gente - e nem eles precisam da gente para aprender as técnicas e a disciplina de um medium. Tal conhecimento é passado informalmente por amigos, pela família, televisão, a rede, livros e filmes. A questão para - artista educador então é: o que especificamente eu tenho a oferecer de útil aos meus estudantes?

Um jeito de começar a dar respostas para esta questão é olhar para os processos e técnicas que nós usamos em nossa disciplina. Como um cantor começa a cantar? Com imitação? Com interpretação? Com improvisação e composição? Que tipo de conhecimento básico um cantor precisa para começar? Em que ordem e com qual relação alguém apreende e desenvolve as ferramentas do canto? Estas são questões complexas e com muitas respostas, mas uma pessoa precisa não ter todas as respostas para começar a desenvolver o currículo. Uma resposta para uma questão pode ser um começo bom o suficiente; se você vê a improvisação como um componente essencial da expressão musical e você tem uma noção de como ela funciona para você enquanto artista então você pode começar a pensar sobre como ensiná-la aos seus estudantes em um dado contexto. O ponto é que nós devemos começar com a questão concreta o que ensinar articulando o mais especificamente possível a habilidade, técnica ou conceito dinâmico com o qual queremos trabalhar com os estudantes.

Muitas vezes educadores artistas são chamados para falar sobre como o processo criativo se desdobra em seus trabalhos com os estudantes, como se o processo fosse uma coisa em si mesmo, desconectado do fazer artístico concreto. Nós entendemos o impulso de educadores que 


\section{REVISTA APOTHEKE}

\section{v.6, n.1, ano 3, julho de 2017 \\ ISSN 2447-1267}

desejam que os estudantes levem algum tipo de aprendizado que transcenda ou que permaneça até depois que a oportunidade de trabalhar numa forma específica de arte tenha passado. Nós também entendemos o instinto a fazer conexões que perpassam as disciplinas e áreas de conteúdo ensinando um único "processo" como qual entrar em cada área, por exemplo, sobrepondo o processo de escrita de rascunhos, feedback, revisão, edição e publicação ao ciclo criativo que alguém usa para preparar uma performance musical - lendo ou aprendendo a música num instrumento, praticando, recebendo feedback, refinando a performance, apresentando o trabalho para uma audiência. Mas esses ciclos criativos na escrita e na música não são fechados, eles variam absurdamente em sua sequência e de acordo com o contexto e também de acordo com a individualidade do artista e de fato podem absolutamente não lançar nenhuma luz útil um ao outro. Nós fazemos um desserviço para os estudantes e para as nossas formas artísticas quando tentamos simplificar e reduzir a uma fórmula os processos altamente complexos e frequentemente espontâneos que atravessamos para fazer arte. Frequentemente, na busca de processos e habilidades "transferíveis" nós ofuscamos precisamente $\circ$ que é interessante e excitante em se trabalhar uma disciplina - o fato de que ela é específica a um medium.

Uma abordagem semântica demasiadamente simplificada para descrever os processos multifacetados de criação numa forma artística achata e desnecessariamente esquematiza o processo criativo fluido e altamente individualizado que os seres humanos usam para fazer arte e para dar sentido à arte. Isto também pressupõe que todos os artistas trabalhando com um médium trabalham da mesma maneira - que todos os artistas usam o mesmo passo a passo para a criação, todos os pintores trabalhando com tinta a óleo e 


\section{REVISTA APOTHEKE}

\section{v.6, n.1, ano 3, julho de 2017 \\ ISSN 2447-1267}

começam da mesma maneira com pequenos estudos e então pintam, e então recebem feedback dos seus pares, e então pintam um pouco mais, esboçam uma apresentação do artista etc. Tal esquematização e demasiada ênfase no processo pode interferir na habilidade do estudante de desenvolver o seu próprio processo, baseado numa reação aos métodos estabelecidos. A fim de desenvolver um trabalho original num meio artístico (médium) você tem que ter sim um senso dos processos do passado, mas você também precisa de espaço para modificá-los ou mesmo substituí-los.

Ainda, um processo artístico não é um mistério impenetrável . Ele pode ser discriminado e, em alguma medida ensinado. O desafio de ensinar um processo é dado pelo fato de que um processo pode ser específico para um único artista (e único estudante) e muitos de nós ensinamos em circunstâncias em que temos um tempo limitado para trabalhar com cada estudante individualmente. Nós precisamos inventar algum jeito para comunicar ideias gerais sobre processo que sejam úteis para um amplo número de estudantes. Muitas vezes, em ordem de vender nossos serviços ou de tornar nossa presença viável e de valor em um ambiente educacional específico nós precisamos ser capazes de comunicar nosso processo artístico para educadores e administradores explicando nosso processo (ou processos) Explicar o processo também pode ajudar vocês a criar uma conexão significativa, não apenas retórica, para educadores e administradores entre sua prática de ensino e prioridades educacionais comuns que eles possam ter para os estudantes tais como o desenvolvimento de "habilidades de pensamento de alta ordem" tais como aplicação, análise, síntese e avaliação. Também é útil para explicar a professores e administradores quais aspectos do seu processo criativo ( nós lhe aconselharíamos a manter esta explicação relacionada à disciplina específica) você 


\section{REVISTA APOTHEKE}

\section{v.6, n.1, ano 3, julho de 2017 \\ ISSN 2447-1267}

planeja enfatizar quando ensina. Isto tornará mais fácil para eles apoiar o seu currículo a partir do deles próprios e a fazer conexões com outros processos com os quais eles engajam os estudantes.

Enquanto uma poeta, Becca encontrou uma solução que é pensar sobre diferentes pontos de entrada que a permitem aplicar seu conteúdo e as habilidades e técnicas numa forma de arte para fazer alguma coisa específica. Por pontos de entrada queremos dizer modos pelos quais alguém pode adentrar na feitura de alguma coisa. Ela frequentemente dá aos estudantes um roteiro de poema - uma linha, outro poema, uma imagem ou todos os três. Frequentemente os estudantes e Becca pensam juntos para vir com alguma coisa a partir destes roteiros ou matéria prima. Este é um ponto de entrada inicial válido dentro da fase inicial do ciclo criativo; vir com ideias que podem ser pontos de partida. Ela ensina aos estudantes explicitamente como esta "fase" é chamada e pede a eles que escrevam sobre ela ( por exemplo, Passo Um: Brainstorming ) ? Não. Ela se importa se eles sabem em qual fase eles estão? Não. Ao invés disso, ela quer que eles façam o brainstorm e surjam com ideais interessantes e convincentes para escrever sobre. Ela pode dizer a eles como forma de introdução que poesias tiram suas ideias de todos os tipos de coisas e ler outros poemas é um jeito para começar a desenvolver tais ideias. Como artistas educadores, precisamos saber muitos pontos de entrada (mesmo que nós mesmos usemos apenas um ou dois e de modos que poderiam desconcertar os estudantes) e compartilhar estes pontos de entrada com os estudantes para que eles possam encontrar seu próprio caminho no trabalho de criação.

Ao passo que nós não achamos que alguém precisa ensinar o processo criativo explicitamente ou que os estudantes precisem articular seu próprio processo 


\section{REVISTA APOTHEKE}

\section{v.6, n.1, ano 3, julho de 2017 \\ ISSN 2447-1267}

explicitamente nós pensamos que é essencial para o artista educador estar ciente de onde um estudante está em seu próprio processo criativo ou ciclo. Tal consciência é uma parte importante no desenvolvimento de uma sequência de ensinolfatura com os estudantes. Uma pessoa precisa saber que ferramentas e técnicas serão disponibilizadas aos estudantes quando eles começam um projeto ou exercício pela primeira vez e que ferramentas e técnicas podem ser úteis aos estudantes quando eles pensam que terminaram um primeiro esboço ou interação. É onde você quer que eles parem por enquanto? Ou você precisa puxá-los mais na revisão e refinamento de suas ideias iniciais? O que eles precisam saber a fim de estarem aptos a fazê-lo com sucesso? Você planejou sua lição ou lições de tal maneira que você está oferecendo a quantidade certa de conhecimento e suporte nos tempos certos?

Como artistas nós vivemos nosso próprio processo criativo, nós podemos raramente ficar em uma fase por muito tempo, ou nós podemos facilmente e inconscientemente deslizar entre fases. Nós começamos um trabalho e o revisamos conforme vamos fazendo - talvez a gente peça uma opinião externa, talvez não. Talvez nós já tenhamos um senso internalizado sobre o que se aprece com qualidade, então nós atiramos para esse lado. Ou talvez nós estejamos tentando expandir ou mesmo explodir nossas noções prévias de qualidade ou estéticas pré existentes e isso direciona a um processo diferente. Editar pode ser um fator dentro de nossa fase inicial de criação, acontece então que nós não rascunhamos ou escrevemos cada uma das ideias estúpidas que aparecem em nossa cabeça. Nós podemos aprender a editar a nós mesmos conforme desenvolvemos experiência e maturidade. Ou podemos trabalhar de um jeito completamente intuitivo e improvisado - nunca editando e nunca refletindo - apenas criando material bruto. Este pode ser um jeito não crítico 


\section{REVISTA APOTHEKE}

v.6, n.1, ano 3, julho de 2017

ISSN 2447-1267

de trabalhar (apesar de que pode gerar bom trabalho em alguns casos), ou pode ser um jeito de trabalhar criticamente e seletivamente no momento presente escolhendo que nota vai tocar, ou palavras para escrever ou dizer baseado nas experiências passadas e nas demandas dinâmica do momento.

Nosso ponto é que devido ao fato de que frequentemente se pede a artistas educadores que explicitamente ensinem um processo criativo específico ou estaticamente definido, nós acabamos esquecendo como que é realmente experimentar nosso próprio processo e quão bagunçado e incipiente ele pode ser. Nós precisamos perguntar por que importa se os estudantes sabem onde eles estão em um processo específico. Qual o objetivo de tal abordagem? Por que nos foi pedido para ensinar isto? Isto poderia ser, de fato, não ensinar aos estudantes a serem mais criativos, mas ao invés de disso insuflar neles a falsa noção de que a criatividade surge seguindo um processo particular ou uma série de passos? Pedir aos estudantes que parem e reflitam onde eles estão do processo criativo e como eles estão lidando com isso é pedir que eles removam a si mesmos de realmente criar alguma coisa.

Devido ao fato de que educadores frequentemente não têm tempo, habilidades, dinheiro e recursos para acessar a arte dos estudantes e o processo de criação artística, eles crescentemente se voltam para acessar o pensar sobre o fazer artístico. Esta tendência também é guiada pela crescente ênfase no uso do ensino de artes para treinar estudantes em comportamentos particulares e hábitos da mente, e por outras tendências em educação altamente utilitaristas e comportamentalistas. Então é comum para instituições e escolas de arte educação pedir que os artistas educadores documentem a reflexão dos estudantes sobre o processo extensivamente. Frequentemente a 


\section{REVISTA APOTHEKE}

\section{v.6, n.1, ano 3, julho de 2017 \\ ISSN 2447-1267}

documentação que nos é pedida é enquadrada de um jeito direcionado, com uma agenda implícita ou explícita de provar que uma forma particular de ensino ou modificação de comportamento está acontecendo. Pode nos ser solicitado que coloquemos os estudantes a refletir sobre como eles navegaram uma fase criativa inicial e como então usaram o feedback para refinar o seu trabalho, ou como eles tentaram experimentação após olhar para o trabalho de outro estudante. Ao passo que isso pode ser interessante e útil para se explorar com os estudantes, mais frequente do que nunca, as questões são postas de forma superficial com o objetivo de prover algum tipo de prova de que os estudantes aprenderam algo real sobre "criatividade" ou alguma outra habilidade intangível.

Nós não estamos dizendo que tal aprendizagem não acontece, mas ao invés disso que esta ênfase torna uma experiência de criação artística, onde o trabalho é o ponto e os estudantes os artistas, em uma experiência avaliativa na qual o desenvolvimento cognitivo ou comportamental do estudante é o ponto. Este pode ser o quadro maior do ponto de vista do educador ou administrador, mas se isto se torna - marco na sala de aula ou estúdio é um grande obstáculo à criação artística do estudante. O tipo de questão que estudantes e artistas educadores deveriam estar considerando é: o trabalho é interessante? Ele faz um uso original e efetivo das técnicas e habilidades estudadas? 0 trabalho reflete inovação e experimentação com as técnicas sendo ensinadas? Se todos os trabalhos parecem semelhantes e não evidenciam invenção, então nenhuma quantidade de reflexão sobre o processo irá ensinar "criatividade". Desde os estágios iniciais da criação do currículo nós precisamos manter as ferramentas, tempo e espaço para a invenção e inovação em um medium por parte dos estudantes no centro do nosso planejamento. 


\section{REVISTA APOTHEKE}

\section{v.6, n.1, ano 3, julho de 2017 \\ ISSN 2447-1267}

Isto não é sugerir que os estudantes não devem aprender o vocabulário de um medium, eles podem e devem fazer isso a fim de maximizar sua habilidade de criticar e desenvolver o seu próprio trabalho e o de outros artistas. Mas a habilidade de falar sobre 0 trabalho não é 0 essencial. Alguns estudantes trabalham seriamente e criam um trabalho artístico de extrema qualidade, mas têm grande dificuldade em falar sobre como o fizeram ou por quê. Estes estudantes falharam? Nós falhamos? Certamente não. Tais estudantes simplesmente não são verbalmente treinados ou fluentes o suficiente para falar sobre seu trabalho nestes termos, ou as fontes do seu trabalho podem ser, parcial ou totalmente, inconscientes. Tal dificuldade em verbalizar sobre o trabalho não significa que os estudantes não tenham internalizado noções sobre o que significa trabalhar com sucesso em um médium ou forma artística particular. Olhe para o trabalho deles. Cheque de novo com eles em sete, ou doze ou vinte anos e veja o que eles tiraram da experiência e prazer de trabalhar diligentemente e autenticamente em uma forma artística. Se eles trabalharam em um cenário no qual eles podiam criar livremente e tirar seus próprios significados da experiência, então mais certamente eles tiraram um grande proveito e um prazeroso insight e, talvez mais importante, eles levaram uma percepção de si mesmos como artistas. Ensinar e aprender sobre como falar e escrever sobre arte pode certamente ser parte do nosso trabalho com estudantes, mas ela tem que ser secundária a ensinar e aprender sobre fazer arte. ${ }^{56}$

56 DIREITOS DE TRADUÇÃO EM LINGUA PORTUGUESA FORAM AUTORIZADOS PELOS AUTORES AOS GRUPO DE ESTUDOS ESTÚDIO DE PINTURA APOTHEKE. 